\title{
Substratos e sistemas de produção de porta enxerto de citrus em cultivo protegido
}

\section{Substrates and door graft production systems in citrus protected cultivation}

\author{
Marcus Vinicius Sandoval Paixão ${ }^{1 *}$, Antonio Resende Fernandes ${ }^{1}$, Gustavo Miranda \\ Cremonini ${ }^{1}$, Lucas Novelli Ziviani ${ }^{1}$, Jusciane Marques de Jesus ${ }^{1}$, Carlos Avelino de Sousa \\ Pancieri $^{1}$
}

\begin{abstract}
RESUMO
Para a produção de mudas de qualidade, é importante que se utilize substratos de boa qualidade física, química e biológica, fator primordial na produção de porta enxerto para mudas de citrus. No mercado, existem poucas marcas de substratos para produção de mudas de citrus, o que encarece o preço final da muda, dificultando o trabalho de pequenos viveiristas. Utilizando os substratos comerciais vermiculita e bioplant ${ }^{\circledR}$, areia e terra em tubetes, e tratamento em canteiro convencional com solo+esterco bovino (3:1), em ambiente protegido, a pesquisa teve como objetivo avaliar emergência e o crescimento de plântulas do porta enxerto limão 'Galego' no sistema de formação em tubetes com diferentes substratos e no sistema convencional de canteiros. O sistema de canteiros com mistura solo+esterco bovino, em ambiente protegido, mostrou maior precocidade, maior eficiência e menor custo para produção de porta enxerto limão 'Galego' (Citrus aurantifolia Tanaca).
\end{abstract}

Palavras chave: Limão galego, tubetes, canteiros.

\section{ABSTRACT}

For the production of seedlings of quality, it is important to use good substrates physical, chemical and biological, primordial factor in the production of citrus seedlings graft port. In the market, there are few brands of substrates for seedlings production of citrus, which makes the final Prince of the changes, hindering the work of small nurseries. Using the vermiculite and bioplant ${ }^{\circledR}$ commercial substrates, sand and earth in cells, and treatment in conventional construction site with soil + cow manure (3:1) in a protected environment, the research aimed to evaluate emergency and seedling growth of port lemon graft Galician in the training system in cells different substrates and in the conventional system of construction sites. The system of construction sites with soil mixture + cow manure, in protectd environment, showed greater precocity, greater efficiency and lower cost for producing graft lime 'Galician' port (Citrus aurantifolia, Tanaca).

Index terms: Lemon galician, tubes, construction sites.

\footnotetext{
${ }^{1}$ Instituto Federal do Espírito Santo

*E-mail: mvspaixao@gmail.com
} 


\section{INTRODUÇÃO}

Um dos fatores fundamentais para o desenvolvimento da citricultura é a muda, pois constitue a base da formação dos pomares e terão reflexo durante toda a sua vida útil (REZENDE et al., 2010).

A escolha do substrato é de fundamental importância, pois é onde o sistema radicular irá desenvolver-se, determinando o crescimento da parte aérea em tubete, até o momento da repicagem.

Substrato tem por finalidade manter as mudas durante o período de desenvolvimento, proporcionando umidade e nutrientes, permitir o arejamento nas raizes, além de criar um ambiente escuro ou opaco reduzindo a penetração da luz (HARTMANN et al., 2011). Deve ser livre de pragas e doenças, e ter fertilidade suficiente para que as mudas desenvolvam sem apresentar déficit nutricional para o desenvolvimento de suas raízes.

A semeadura dos porta enxertos cítricos pode ser feita em tubetes plásticos, bandejas ou em embalagens definitivas, sendo que os tubetes de $50 \mathrm{~cm}^{3}$, de forma cônica, com quatro a seis estrias longitudinais, são os mais recomendados, e, quando os porta enxertos apresentam de 10 a $15 \mathrm{~cm}$ de altura, o que ocorre após 3-5 meses da semeadura, deve ser feito o transplantio para recipientes maiores $\left(5\right.$ a $\left.7 \mathrm{dm}^{3}\right)$, a fim de completar sua formação, devendo ser conduzidos em haste única até o momento da enxertia (OLIVEIRA et al., 2008).

Boaventura et al. (2004) destacam a importância da produção de mudas cítricas em ambiente protegido observada a maior eficiência e garantia de competitividade da citricultura como agronegócio pela produção de mudas descontaminadas com doenças de substratos como nematóides, gomose, clorose variegada dos citrus (CVC) e o cancro cítrico. A escolha do método de produção e substrato a ser usado, é determinante para produção de mudas de qualidade e de custo acessível para o produtor, devendo este procurar o substrato e o método que melhor se adapte as condições locais.

O substrato é determinante no desenvolvimento sadio das mudas de porta enxerto, uma vez que é a primeira fonte nutritiva e qualquer mudança na sua composição pode alterar a formação das plantas. A função do substrato é servir de suporte estrutural para as plantas, além de fornecer água e nutrientes (FERREIRA et al., 2009; FERMINO et al., 2010). 
No Espírito Santo, a variação de substratos na produção de mudas é grande, como o uso de misturas de solo com esterco, adicionando fertilizantes (NPK), ao uso de substrato comercial, adicionando fertilizantes de liberação lenta, sendo também utilizado esterco de curral (PAIXÃO et al., 2012).

Diversos materiais têm sido utilizados na formação de mudas em tubetes, citando a vermiculita, a serragem, o bagaço de cana, casca de pinus, casca de arroz carbonizada e a turfa (BOSA et al., 2003). Há relatos de que a adição de casca de arroz carbonizada a outros materiais contribuiu na melhoria das propriedades físicas do substrato (DIAS et al., 2010).

Dessa forma, a utilização de materiais de fácil e constante disponibilidade nas regiões produtoras, que possam ser utilizado na composição de substratos, é de fundamental importância para baratear os custos de produção de mudas e dar suporte às modificações exigidas para modernização da citricultura (LOPES, ALBUQUERQUE \& MOURA, 2007).

Objetivou-se avaliar a emergência e o crescimento de plântulas do porta enxerto limão 'Galego' no sistema de formação em tubetes com diferentes substratos e em canteiros em condições de cultivo protegido.

\section{MATERIAL E MÉTODOS}

$\mathrm{O}$ experimento foi conduzido no setor de viveiricultura,com tela de poliolefina (50\% de sombreamento) do Instituto Federal de Ensino Superior de Santa Teresa (IFESCampus Santa Teresa), nos meses de junho a outubro de 2015, localizado na meso região Central Espírito-Santense, em Santa Teresa-ES, coordenadas geográficas 1956’12”S e $40^{\circ} 35^{\prime} 28^{\prime \prime} \mathrm{W}$, com altitude de $175 \mathrm{~m}$. O clima da região caracteriza-se como Cwa, mesotérmico, com estação seca no inverno e forte pluviosidade no verão (classificação de Köppen) (ALVARES et al., 2013), com precipitação anual média de 1.404,2 mm e temperatura média anual de $19,9^{\circ} \mathrm{C}$, com média máxima de $32,8^{\circ} \mathrm{C}$ e mínima de $10,6{ }^{\circ} \mathrm{C}$ (INCAPER, 2011).

Foram avaliados dois sistema de produção de mudas de porta enxerto de limão 'Galego' (Citrus aurantifolia Tanaca): em tubetes e em canteiro (testemunha). Os substratos avaliados nos tubetes foram terra, areia, bioplant ${ }^{\circledR}$ e vermiculita (textura média), e no canteiro, foram utilizados terra e esterco bovino curtido e peneirado (quatro 
mash) na proporção de 3:1. A análise física do solo revelou ser o mesmo de classe textural argilosa $(368,72 \mathrm{~g} / \mathrm{Kg}$ areia; $53,60 \mathrm{~g} / \mathrm{Kg}$ silte; $577,49 \mathrm{~g} / \mathrm{Kg}$ argila) e a análise química revelou os seguintes valores nutricionais: $\mathrm{P}=32 \mathrm{mg} / \mathrm{dm}^{3} ; \mathrm{K}=306 \mathrm{mg} / \mathrm{dm}^{3} ; \mathrm{Ca}=1,60$ $\mathrm{cmol} / \mathrm{dm}^{3} ; \quad \mathrm{Mg}=1,58 \mathrm{cmol} / \mathrm{dm}^{3} ; \mathrm{H}+\mathrm{Al}=1,73 \mathrm{cmol} / \mathrm{dm}^{3} ; \mathrm{SB}=3,96 \mathrm{cmol} / \mathrm{dm}^{3} ; \mathrm{CTC}=$ $3,96 \mathrm{cmol} / \mathrm{dm}^{3} ; \mathrm{CTC}$ a pH $7=5,69 \mathrm{cmol} / \mathrm{dm}^{3} ; \mathrm{MO}=8,82 \mathrm{~g} / \mathrm{Kg} ; \mathrm{pH}=6,15$. A mistura do canteiro revelou ser de classe textural argilosa $(400,94 \mathrm{~g} / \mathrm{Kg}$ areia; $54,63 \mathrm{~g} / \mathrm{Kg}$ silte; $544,43 \mathrm{~g} / \mathrm{Kg}$ argila) e a análise química revelou os seguintes valores nutricionais: $\mathrm{P}=$ $56,79 \mathrm{mg} / \mathrm{dm}^{3} ; \mathrm{K}=836 \mathrm{mg} / \mathrm{dm}^{3} ; \mathrm{Ca}=3,18 \mathrm{cmol} / \mathrm{dm}^{3} ; \mathrm{Mg}=2,77 \mathrm{cmol} / \mathrm{dm}^{3} ; \mathrm{H}+\mathrm{Al}=$ $1,90 \mathrm{cmol} / \mathrm{dm}^{3} ; \mathrm{SB}=8,59 \mathrm{cmol} / \mathrm{dm}^{3} ; \mathrm{CTC}=8,59 \mathrm{cmol} / \mathrm{dm}^{3} ;$ CTC a $\mathrm{pH} 7=10,49$ $\mathrm{cmol} / \mathrm{dm}^{3} ; \mathrm{MO}=27,16 \mathrm{~g} / \mathrm{Kg} ; \mathrm{pH}=6,47$.

O delineamento utilizado foi em blocos casualizados, com quatro repetições de 25 sementes. Os blocos foram formados por oito bandejas com 54 tubetes com capacidade para $290 \mathrm{~cm}^{3}$, que foram mantidas em bancadas suspensas a $90 \mathrm{~cm}$ do solo, e as parcelas foram constituídas por 25 tubetes, acrescidas de uma parcela experimental em cada fileira, correspondendo ao controle (testemunha, canteiro confeccionado com a mistura terra+esterco bovino).

A semeadura foi realizada colocando-se uma semente de limão 'Galego' (Citrus aurantifolia Tanaca) por tubete, e em canteiros confeccionados com sulcos de $25 \mathrm{~cm}$, na profundidade de um $\mathrm{cm}$. As irrigações foram feitas diariamente, utilizando-se microaspersores durante toda a condução do experimento, com três regas diárias às 8, 12 e 16 horas, com duração de 15 minutos .

As avaliações foram feitas diariamente da porcentagem de emergência (E), o índice de velocidade de emergência (IVE) (MAGUIRE, 1962) e o tempo médio de emergência (TME) (LABORIAU \& VALADARES, 1976). Após 120 dias da semeadura, foram coletadas dez mudas de cada tratamento e avaliados o diâmetro do coleto (DC), comprimento da parte aérea (CPA), número de folhas (NF), comprimento da raiz (CR), volume das raízes (VR), massa seca das folhas (MSF) e do sistema radicular (MSR), após secagem em estufa em $70^{\circ} \mathrm{C}$ por $72 \mathrm{~h}$.

Os dados foram submetidos à análise de variância e as médias de cada característica comparadas pelo teste de Dunnett em nível de 5\% de probabilidade, sendo considerado como padrão o tratamento de semeadura nos canteiros. A avaliação das médias foi feita pelo teste de Tocher. Todas as análises foram feitas utilizando-se o programa Genes (CRUZ, 2013). 


\section{RESULTADOS E DISCUSSÃO}

De acordo com a análise de variância verifica-se que houve diferença estatística entre os tratamentos e o preparo padrão de mudas para todas as variáveis avaliadas (Tabela 1).

Tabela 1 - Resumo da análise de variância para emergência e vigor de plântulas de limão galego submetidos a diferentes substratos

\begin{tabular}{|c|c|c|c|c|c|c|}
\hline \multirow{2}{*}{$\begin{array}{l}\text { Fontes de } \\
\text { variação }\end{array}$} & \multirow{2}{*}{$\begin{array}{l}\text { Graus de } \\
\text { liberdade }\end{array}$} & \multicolumn{5}{|c|}{ Quadrado médio } \\
\hline & & $E$ & IVE & TME & $\mathrm{NF}$ & $\mathrm{DC}$ \\
\hline Blocos & 3 & 14,93 & 0,0005 & 0,36 & 1,67 & 440,18 \\
\hline (Tratamentos) & (4) & $111,20 *$ & $0,0194 * *$ & $9,29 * *$ & $44,37 * *$ & $6680,67 * *$ \\
\hline Substratos (S) & 3 & $99,67 *$ & $0,0102 * *$ & $7,73 * *$ & $13,23^{* * *}$ & $3114,08 *$ \\
\hline S x Padrão & 1 & $145,80 *$ & $0,0467 * *$ & $13,95^{* *}$ & $137,81 * *$ & $188180,45^{* *}$ \\
\hline Resíduo & 12 & 24,27 & 0,0015 & 0,23 & 0,71 & 647,64 \\
\hline Média & & 93,60 & 0,89 & 27,13 & 5,50 & 227,95 \\
\hline $\mathrm{CV}_{(\%)}$ & & 5,26 & 4,36 & 1,78 & 15,30 & 11,16 \\
\hline \multirow{2}{*}{$\begin{array}{c}\text { Fontes de } \\
\text { variação }\end{array}$} & Graus de & \multicolumn{5}{|c|}{ Quadrado médio } \\
\hline & liberdade & $\mathrm{CPA}$ & $\overline{C R}$ & MSF & MSR & VR \\
\hline Blocos & 3 & 0,80 & 2,07 & 12,60 & 13,20 & 0,010 \\
\hline (Tratamentos) & (4) & $113,75 * *$ & $54,53 * *$ & $109482,70 * *$ & $8021,95 * *$ & $0,198 * *$ \\
\hline Substratos (S) & 3 & $2,51^{\mathrm{ns}}$ & $2,83^{*}$ & $8790,92 * *$ & $5060,23 * *$ & 0,133 ** \\
\hline S x Padrão & 1 & $447,46 * *$ & $209,63 * *$ & $411558,05 * *$ & $16907,11 * *$ & $0,392 * *$ \\
\hline Resíduo & 12 & 1,19 & 0,78 & 5,60 & 22,45 & 0,009 \\
\hline Média & & 7,49 & 20,25 & 180,10 & 143,60 & 0,75 \\
\hline $\mathrm{CV}_{(\%)}$ & & 14,55 & 4,35 & 1,31 & 3,30 & 12,73 \\
\hline
\end{tabular}

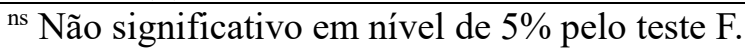

*,** Significativo em níveis de 5 e $1 \%$, respectivamente pelo teste $\mathrm{F}$.

$\mathrm{E}=$ emergência, em \%; IVE = índice de velocidade de emergência; TME = tempo médio de emergência; $\mathrm{NF}=$ número de folhas; $\mathrm{DC}=$ diâmetro de caule, em $\mathrm{mm} ; \mathrm{CPA}=$ comprimento da parte aérea, em $\mathrm{cm} ; \mathrm{CR}=$ comprimento de raízes, em $\mathrm{cm}$; $\mathrm{MSF}$ = matéria seca de folhas por plântula, em mg; MSR = matéria seca de raízes por plântula, em mg; VR = volume de raízes, em $\mathrm{cm}^{3}$.

A credibilidade destes resultados é fortalecida pelos valores de coeficiente de variação que variaram de 1,31\% para massa seca de folhas por plântula (MSF) até 15,30\% para número de folhas por plântula (NF). Estes valores estão classificados entre baixo e médio segundo Pimentel-Gomes (2009).

O cultivo em canteiro apresentou médias estatisticamente superiores para a maioria das características avaliadas. Os substratos solo, areia, bioplant ${ }^{\circledR}$ e vermiculita, no tubete, permitiram, respectivamente, que a E, IVE e TME fossem similares à testemunha (Tabela 2). 
Tabela 2 - Médias de dez características na emergência e vigor de plântulas de limão galego submetidos a diferentes substratos

\begin{tabular}{cccccc}
\hline Tratamento & E & IVE & TME & NF & DC \\
\hline Solo, em tubetes & $89,00 \mathrm{bc}$ & $0,80 \mathrm{c}$ & $28,87 \mathrm{c}$ & $4,00 \mathrm{c}$ & $214,25 \mathrm{bc}$ \\
Areia, em tubetes & $96,00 \mathrm{abc}$ & $0,87 \mathrm{bc}$ & $28,53 \mathrm{c}$ & $6,75 \mathrm{~b}$ & $228,00 \mathrm{~b}$ \\
Bioplant, em tubetes & $97,00 \mathrm{ab}$ & $0,93 \mathrm{ab}$ & $26,88 \mathrm{~b}$ & $2,50 \mathrm{c}$ & $173,25 \mathrm{c}$ \\
Vermiculita, em tubetes & $87,00 \mathrm{c}$ & $0,86 \mathrm{bc}$ & $25,92 \mathrm{ab}$ & $3,50 \mathrm{c}$ & $236,00 \mathrm{~b}$ \\
\hline Solo + esterco, em canteiro & $99,00 \mathrm{a}$ & $0,99 \mathrm{a}$ & $25,46 \mathrm{a}$ & $10,75 \mathrm{a}$ & $288,25 \mathrm{a}$ \\
\hline DMS & 9,79 & 0,077 & 0,96 & 1,67 & 50,57 \\
\hline Tratamento & CPA & CR & MSF & MSR & VR \\
\hline Solo, em tubetes & $4,45 \mathrm{~b}$ & $21,20 \mathrm{~b}$ & $89,00 \mathrm{~d}$ & $124,75 \mathrm{~d}$ & $0,48 \mathrm{c}$ \\
Areia, em tubetes & $6,25 \mathrm{~b}$ & $22,32 \mathrm{~b}$ & $172,50 \mathrm{~b}$ & $150,00 \mathrm{c}$ & $0,78 \mathrm{~b}$ \\
Bioplant, em tubetes & $4,73 \mathrm{~b}$ & $21,13 \mathrm{~b}$ & $62,50 \mathrm{e}$ & $80,75 \mathrm{e}$ & $0,58 \mathrm{c}$ \\
Vermiculita, em tubetes & $5,08 \mathrm{~b}$ & $22,82 \mathrm{~b}$ & $109,50 \mathrm{c}$ & $160,75 \mathrm{~b}$ & $0,87 \mathrm{a}$ \\
\hline Solo + esterco, em canteiro & $16,95 \mathrm{a}$ & $13,78 \mathrm{a}$ & $467,00 \mathrm{a}$ & $201,75 \mathrm{a}$ & $1,03 \mathrm{a}$ \\
\hline DMS & 2,17 & 1,75 & 4,70 & 9,41 & 0,19 \\
\hline
\end{tabular}

Médias dos tratamentos, substratos em tubetes, seguidos da letra a, em cada coluna, não diferem do padrão (Solo + esterco, em canteiro) em nível de $5 \%$ de probabilidade pelo teste de Dunnett.

$\mathrm{E}=$ emergência, em \%; IVE = índice de velocidade de emergência; TME = tempo médio de emergência; $\mathrm{NF}=$ número de folhas; $\mathrm{DC}=$ diâmetro de caule, em $\mathrm{mm} ; \mathrm{CPA}=$ comprimento da parte aérea, em $\mathrm{cm} ; \mathrm{CR}=$ comprimento de raízes, em $\mathrm{cm} ; \mathrm{MSF}=$ matéria seca de folhas por plântula, em mg; MSR = matéria seca de raízes por plântula, em mg; VR = volume de raízes, $\mathrm{em} \mathrm{cm}^{3}$.

Jabur \& Martins (2002), trabalhando com limão 'Cravo' e tangerina 'Cleópatra', conseguiram as melhores médias de germinação com o substrato vermiculita.

Características das plântulas relacionadas à parte aérea (NF, DC, CPA, MSF), importantes no processo de enxertia, apresentaram melhor resultado para o cultivo em canteiro. A condição de cultivo em tubetes permitiu a obtenção de plântulas com maior CR e VR em relação às cultivadas em canteiro. O tubete apresenta aeração maior que o canteiro, a forma geométrica e as ranhuras nas paredes internas do tubete condicionam crescimento radicular longitudinal maior, e o crescimento longitudinal radicular é estimulado por condições de déficit hídrico (TAIZ et al., 2017), condição que o tubete tem chances de apresentar dado o seu baixo volume. Nestas condições, tratamentos no tubete, promoveu ao sistema radicular um menor acúmulo de matéria seca e volume em relação ao tratamento solo+esterco bovino em canteiro. O cultivo em canteiro, por disponibilizar maior volume de substrato, nutrientes e água, permitiu o maior acúmulo de matéria seca (Tabela 2).

A capacidade do recipiente, por ser diretamente proporcional à disponibilidade de recursos como água e nutrientes à planta, bem como acomodação do sistema radicular, é um fator decisivo para determinar a velocidade de crescimento do porta-enxerto e da muda, e indicar a viabilidade técnico-econômica do empreendimento (GIRARDI et al., 
2007a). O volume do recipiente pode influenciar, ainda, o desempenho de mudas frutíferas, Resende et al. (2010) citam que o acúmulo de matéria seca até os noventa dias é lento devido ao pequeno espaço ocupado pelas raízes, que explora somente o substrato já esgotado do tubete.

O maior crescimento das plântulas no solo+esterco foi evidente, com valores médios significativamente superiores aos outros tratamentos; a maior MSF, NF, CPA e DC observada é característica marcante para caracterizar o melhor desenvolvimento das plântulas (Tabela 2).

A massa seca acumulada pode representar melhor o crescimento que a massa verde, a quantidade de água absorvida pela muda pode variar de substrato para substrato, de acordo com os fatores climáticos como temperatura e arejamento dentro do substrato, o que pode fazer com que a massa seca seja melhor indicador de desenvolvimento que a massa verde.

O desenvolvimento radicular das mudas no substrato solo+esterco foi bem superiores aos outros tratamentos; as médias observadas para CR, MSR e VR (Tabela 2), evidenciam que o espaço disponível no canteiro pode ser fundamental no desenvolvimento das plântulas. Girardi et al. (2007b) verificaram que o volume de substrato maior é fundamental na obtenção de mudas mais vigorosas em menor tempo. Sementes de porta-enxertos cítricos semeadas diretamente em sacolas de 1,7 L atingiram ponto ideal de subenxertia em menor tempo, entre 100 a 150 dias após a semeadura, além de apresentarem plantas maiores e com sistema radicular adequado, porém com custo de produção inicial superior ao sistema de produção em tubetes de $290 \mathrm{~mL}$.

Silva et al. (2011) utilizando resíduos orgânicos de casca de arroz carbonizada e turfa combinado com o fertilizante de liberação lenta Osmocote ${ }^{\circledR}$ observaram maior influência no desenvolvimento das mudas de porta-enxerto de limão cravo, propiciando mudas com melhor qualidade.

Resultados similares sobre a influência do substrato no desenvolvimento vegetativo de porta-enxertos cítricos produzidos em recipientes, foram observados por Fochesato et al. (2007), sendo que o substrato comercial composto de cascas processadas e enriquecidas, vermiculita expandida, perlita expandida e turfa, possibilitaram maior desenvolvimento vegetativo aos porta-enxertos. Franco et al. (2007) encontraram melhores resultados com os substratos Plantmax ${ }^{\circledR}$ e Tropstrato ${ }^{\circledR}$ com vermiculita, que 
induziram maior precocidade, pois as plantas de todos os porta-enxertos utilizados atingiram maior altura nesses substratos.

Fernandes, Gomes \& Mendonça (2012) citam que não há um substrato único, que possa ser recomendado para o cultivo dos diferentes porta-enxertos cítricos, ficando esta escolha condicionada a variedade que se está produzindo e a região de produção, pela disponibilidade de materiais, sendo que a mistura de diferentes materiais presentes na região, que permita adequada característica física, com custo competitivo, é o mais recomendado para a produção de mudas cítricas em recipientes. Diferentemente do citado, observou-se que em canteiros em ambiente protegido, considerando as características estudadas, foram obtidas mudas com melhor desenvolvimento e em melhores condições para enxertia (Tabela 2).

Observa-se que as mudas em solo+esterco bovino, atingiram aos cento e vinte dias, porte de repicagem com alturas de 16,95 cm (Tabela 2), que foram bem superiores à média recomendada, que é de $10 \mathrm{~cm}$ (JABUR \& MARTINS, 2002).

Considerando os agrupamentos utilizados em tubetes e o grupo padrão com solo+esterco bovino em canteiro (Tabela 3), e os custos para implantação destes grupos, observou-se que além da melhor qualidade da muda produzida em canteiros convencionais em ambiente protegido, deve-se considerar o aspecto econômico da produção, principalmente porque os custos de produção para plantio em tubetes foram maiores que os custos utilizados para o plantio em canteiros, com substrato solo+esterco bovino (3:1) (Tabela 2), assim como, os tratamentos utilizados e as características observadas para qualificação das plântulas foram melhores nos canteiros, considerando que não há custos de embalagem (tubetes e bandejas) e que a mistura solo+esterco bovino apresenta menor custo e maior facilidade de aquisição do que os substratos comerciais.

Tabela 3 - Agrupamento, pelo método de Tocher, dos tratamentos de preparo de mudas de limão galego com base em dez características na emergência e vigor de plântulas

\begin{tabular}{cc} 
galego com base em dez características na emergência e vigor de plântulas \\
\hline Grupo & Tratamentos de preparo de mudas \\
\hline I & Solo, em tubetes; Areia, em tubetes; Bioplant, em \\
& tubetes; Vermiculita, em tubetes \\
II & Solo + esterco, em canteiro \\
\hline
\end{tabular}

Fonte: Dados do autor 


\section{CONCLUSÃO}

O plantio em canteiro convencional com substrato a base de solo+esterco bovino (3:1) em ambiente protegido, mostrou maior precocidade e melhor desenvolvimento de plântulas para produção de porta enxerto da Cv limão 'Galego' (Citrus aurantifolia, Tanaca).

\section{REFERÊNCIAS}

ALVARES, C.A.; STAPE, J.L.; SENTELHAS, P.C.; GONÇALVES, J.L.M; SPAROVEK, G. Köppen's climate classification map for Brazil. Meteorologische Zeitschrift, v.22, p.711-728. 2013.

BOAVENTURA, P. R. R.; QUAGGIO, J. A.; ABREU, M. F.; BATAGLIA, O. C. Balanço de nutrientes na produção de mudas cítricas cultivadas em substrato. Revista Brasileira de Fruticultura, Jaboticabal - SP, v.26, n.2, p.300-305, 2004.

BOSA, N.; CALVETE, E. O.; KLEIN, V. A.; SUZIN, M. Crescimento de mudas de gipsofila em diferentes substratos. Horticultura Brasileira, Brasília, v.21, n.3, p.514519, 2003.

CRUZ, C. D. Programa Genes: estatística experimental e matrizes, Viçosa: UFV, 2013. $285 \mathrm{p}$.

DIAS, T. J.; FERREIRA, C. S.; SOUZA, V. A. B.; FREIRE, J. L. O.; PEREIRAW. E. Diferentes composições de substratos no crescimento de mudas de genótipos de mangabeira. Revista Engenharia Ambiental, Espírito Santo do Pinhal, v.7, n.3, p.92$107,2010$.

FERMINO, M. H.; GONÇALVES, R. S.; BATTISTIN, A.; SILVEIRA, J. R. P.; BUSNELlO, A. C.; TREVISAM, M. Aproveitamento dos resíduos da produção de conserva de palmito como substrato para plantas. Horticultura Brasileira, Brasília, v.28, p.282-286. 2010.

FERNANDES, L. F.; GOMES, W. A.; MENDONÇA, R. M. N. Substratos na produção de porta-enxertos cítricos em ambiente protegido. Revista Verde, Mossoró, v.7, n.3, p.1$06,2012$.

FERREIRA, M. G. R.; ROCHA, R. B.; GONÇALVES, E. P.; RIBEIRO, G. D. Influência do substrato no crescimento de mudas de cupuaçu (Theobroma grandiflorum Schum.), Acta Scientiarum Agronomy, Maringá, v.31, n.4, p.677-681, 2009.

FRANCO, D.; CAVALCANTE, Í. H. L.; OLIVEIRA, I. V. M.; MARTINS, A. B. G. Avaliação de substratos no desenvolvimento inicial de seis porta-enxertos de citros. Laranja, Cordeirópolis, v.28, n.1-2, p.61-70, 2007. 
FOCHESATO, M. L.; SOUZA, P. V. D.; SCHÄFERI, G.; MACIELI, H. S. Crescimento vegetativo de porta-enxertos de citros produzidos em substratos comerciais. Ciência Rural, Santa Maria, v.37, n.4, p.970-975, 2007.

GIRARDI, E. A.; MOURÃO FILHO, F. A. A.; GRAF, C. C. D.; OLIC, F. B. Vegetative Growth of citrus nursery trees related to the container volume. Fruits, Rio de Janeiro, v.59, p.101-105, 2007a.

GIRARDI, E. A.; MOURÃO FILHO, F. A. A.; PIEDADEM, S. M. S. Vegetative development and production cost of citrus rootstocks in containers for inarching. Pesquisa Agropecuária Brasileira. Brasília, v.42, n.5, p.679-687, 2007 b.

HARTMAnN, H. T.; KESTER, D. E.; DAVIES JR, F. T.; GENEVE, R. L. Plant propagation: principles and practices, 8.ed., 2011. 915p.

JABUR, M. A.; MARTINS, A. B. G. Influência de substratos na formação dos portaenxertos: Limoeiro-cravo (Citrus limonia Osbeck) e tangerineira-cleópatra (Citrus reshni Hort. Ex Tanaka) em ambiente protegido. Revista Brasileira de Fruticultura, Jaboticabal, v.24, n.2, p.514-518, 2002.

LABOURIAU, L. G.; VALADARES, M. E. B. On the germination of seeds Calotropis procera (Ait.). Anais da Academia Brasileira de Ciências, v.48, n.2, p.263-284. 1976.

LOPES, E. B.; ALBUQUERQUE, I. C. DE.; MOURA, F. T. de. Perfil da citricultura de Matinhas-PB, visando ao mercado nacional. Revista Tecnologia \& Ciência Agropecuária, João Pessoa, v.1, n.1, n.1-7, 2007.

MAGUIRE, J. D. Speed of germination - aid in selection and evolution for seedling emergence and vigor. Crop Science, v.2, n.2, p.176-177, 1962.

OLIVEIRA, R. P.; SOARES FILHO, W. S.; PASSOS, O. S.; SCIVITTARO, W. B.; ROCHA, P. S. G. Porta-enxertos para citros. $226^{a}$ Ed. Pelotas: Embrapa Clima Temperado, 2008. 32p.

PIMENTEL-GOMES, F. Estatística experimental. 15. Ed., Piracicaba: Fealq, 2009. $451 \mathrm{p}$.

PAIXÃO, M. V. S.; SCHMILDT, E. R.; MATTIELLO, H. N.; FERREGUETTI, G. A.; ALEXANDRE, R. S. Frações orgânicas e mineral na produção de mudas de mamoeiro. Revista Brasileira de Fruticultura, Jaboticabal, v.34, n.4, p.1105-1112, 2012.

REZENDE, C. F. A.; FERNANDES, E. P.; SILVA, M. F.; LEANDRO, W. M. Crescimento e acúmulo de nutrientes em mudas cítricas cultivadas em ambiente protegido. Biosci. Journal, Uberlândia, v.26, n.3, p.367-375, 2010.

SILVA, E. A.; SILVA, B. M.; COGO, F. D.; OLIVEIRA, L. M. Produção de mudas de porta-enxerto de limão-cravo em tubetes sob diferentes substratos. Enciclopédia Biosfera, Centro Científico Conhecer - Goiânia, v.7, n.1, p.847-855, 2011. 
TAIZ, L.; ZEIGER, E.; MOLLER, I.; MURPHY, A. Fisiologia e desenvolvimento vegetal. 6.ed., Porto Alegre: Artmed, 2017. 888 p.

Recebido em: 01/09/2021

Aprovado em: 25/09/2021

Publicado em: 30/09/2021 